\title{
Consórcios de bibliotecas no Brasil: um desafio à democratização do conhecimento
}

Antônio Marcos Amorim

Mestre em Ciências da Comunicação - Universiddade de São Paulo, Brasil Bibliotecário do Instituto de Psicologia da Universidade de São Paulo, Brasil. Av. Prof. Mello Moraes, 1721 - Cidade Universitária CEP 05508-030 - São Paulo - SP Tel. / Fax: 11 3091-4392 E-mail:amarcos@usp.br

Waldomiro Vergueiro

PhD em Ciências da Comunicação - Professor Associado da Universidade de São Paulo, Brasil. Escola de Comunicações e Artes da Universiddade de São Paulo. Av. Prof. Lúcio Martins Rodrigues, 443 - Cidade Universitária - CEP 05508-900 - São Paulo - SP. Tel. / Fax: 11 3091-4107 E-mail:wdcsverg@usp.br

Discute o impacto da globalização eletrônica e a função desempenhada pelos consórcios de bibliotecas no Brasil, como um elemento de democratização do acesso à informação. Analisa o mercado de publicações científicas e descreve os principais consórcios de bibliotecas latino-americanas em anos recentes. Foi feito estudo de caso de um consórcio de bibliotecas brasileiras - o ProBE, seus benefícios para as bibliotecas e a comunidade científica brasileira, e considerações de seu impacto na promoção de uma maior eqüidade social.

Palavras-chave : Consórcio de bibliotecas - Brasil; Consórcio ProBE; Globalização de publicações científicas; Periódicos eletrônicos.

Recebido em: 10.10.2005

Aceito: 29.03.2006 


\section{Introduçã̃o}

$\bigcirc$ processo de transformação econômica mundial, através da globalização, e a conseqüente criação de uma única economia informacional engendraram uma nova arquitetura mundial, (re)dividindo-o em dois grandes blocos: uma maioria de nações e mercados de excluídos'; e um pequeno grupo de nações ou mercados ricos - ou incluídos - sendo aqueles cada vez mais dependentes destes. Ao mesmo tempo, vivemos num mundo sob a égide da tecnologia de informação: sua principal característica é que a informação, muito mais que outros insumos - como energia, máquinas etc., é uma matéria-prima: são tecnologias para agir sobre a informação, e não apenas informação para agir sobre a tecnologia, como ocorreu com as revoluções tecnológicas anteriores, como bem mostram Dosi, Freeman et al. (1988) apud Castells (1999, p. 77).

A análise de um modelo teórico que englobe todos os fatores envolvidos neste contexto, nos faz deparar com o uso massivo das redes de informação, utilizando-se das novas tecnologias de comunicação, nas quais a Internet é sua mais ampla expressão, bem como todos os avanços obtidos nos anos 1990 nas áreas de telecomunicações e informática. Entretanto, poderse-ia questionar se, considerando a realidade brasileira, marcada pela desigualdade social gritante, a corrupção da classe política e o sucateamento de boa parte de sua economia, os efeitos sociais e econômicos das tecnologias de informação realmente foram percebidos e apropriados, possibilitando um retorno social a estes segmentos menos privilegiados da sociedade brasileira. Aqui, aparecem dados e discursos discrepantes a respeito. Somente para citar um dado, existe um consenso geral de que mais de 50\% da força de trabalho brasileira migrou para o mercado informal, em conseqüência da ampliação do desemprego pelo fechamento de um grande número de micro e pequenas empresas. Um excelente retrato deste panorama é apresentado por um estudo de Dupas (2000, p. 58), o qual aponta que "o chamado setor informal já atinge cerca de $40 \%$ a $70 \%$ do mercado de trabalho".

Considerando que o uso intensivo das tecnologias de informação será tanto mais intensivo quanto maior for a capacidade dessa mesma sociedade em assimilá-las, a sociedade brasileira parece caminhar, simultaneamente, para uma descoberta desse novo meio, assimilando cada vez mais informações, embora não necessariamente mais conhecimentos e utilizando-se das redes de informação numa cadeia crescente. Além disso, boa parte dos cidadãos do país não possui ainda acesso sequer a uma linha telefônica. Reforçando esta teoria, em pesquisa conduzida pelo IBOPE - Instituto Brasileiro de Pesquisas e Estatística -, e publicada na revista semanal Veja por Nogueira e Vargas (2000), foi revelado que

- Brasil já possui 14 milhões de pessoas com acesso à Internet - um em cada dez brasileiros com mais de 16 anos surfaram na web pelo menos uma vez nos últimos três meses [...] $\bigcirc$ acesso à Internet está deixando de ser um privilégio de uma elite com telefone e computador em casa. Existem hoje pelo menos 6,4 milhões de internautas que só podem ser assim chamados pois usam a web no trabalho, em casa, na escola, na universidade ou em outros locais, como os cibercafés.
I Esta terminologia, usada para denominar os excluídos, será aqui adotada para designar as camadas mais pobres e desfavorecidas da sociedade, ainda que alguns pesquisadores não a aprovem, afirmando que sob este conceito há um determinismo tendencioso. 
Uma pesquisa em nove áreas metropolitanas brasileiras, feita em outubro de 2002, e publicada pelo próprio e-IBOPE (2002), apresenta uma preferência pela aquisição de um computador com acesso à Internet - cerca de $61 \%$ dos consumidores -, em comparação à compra de telefones celulares ou à assinatura de TV a cabo. Ainda que estes dados não possam ser generalizados - como, por exemplo, dizer que a maioria dos cidadãos possui acesso à Internet e pode desfrutar de seus benefícios - é evidente que mais pessoas estão utilizando a rede e todas as novas tecnologias acessíveis na América Latina para não ficarem excluídas do grande fluxo informacional que trafega em um mundo simultaneamente global e local.

Outro caso é o da comunicação por telefonia celular, e publicado no artigo Conexão... (2004, p. 40), "que já operava no Brasil, segundo a Anatel, com mais de 57 milhões de aparelhos móveis em agosto de 2004, indicando que mais de $32 \%$ da população possui um celular - isto representa mais que o total de telefones fixos, com 40 milhóes de linhas". Levando em consideração os aspectos mencionados, este artigo tenta observar o impacto da globalização eletrônica, principalmente do ponto de vista do acesso às publicações eletrônicas nas bibliotecas universitárias brasileiras e os benefícios que estas podem trazer, incluindo também a análise do contexto dos consórcios de bibliotecas na América Latina e sua relação direta com o mercado de publicações científicas eletrônicas. Esta pesquisa também procura dar o embasamento para um ponto de vista mais prático, enfocando em especial o desenvolvimento de um consórcio de bibliotecas no Brasil como um estudo de caso - o Consórcio ProBE (AMORIM, 2002).

A análise das atividades do referido consórcio permitiu observar implicações diversas no período de 1999 até 200 I , em que o debate do acesso à informação foi muito favorável. Por esta razão, a pesquisa tentou contrapor o discurso das autoridades e a práxis política do consórcio a um survey, tanto das bibliotecas participantes como de um grande agente de revistas científicas. Também se tentou medir como o consórcio ProBE influenciou o mercado das revistas científicas, controlado por oligopólios, e como as bibliotecas participantes abriram caminho para uma ação econômica e social, modificando a situação atual no que diz respeito ao acesso ao conhecimento científico dos pesquisadores e cientistas brasileiros, e, indiretamente, da sociedade como um todo.

\section{A globalização eletrônica}

A globalização mostra-se com um conjunto de fenômenos complexos, envolvendo diversas variáveis. Ainda que os limites deste artigo não possibilitem um aprofundamento do estudo da literatura sobre globalização, podemos destacar os excelentes estudos da literatura internacional. Entre essas pesquisas, podemos citar os trabalhos de Hirst e Thompson (1992, 1998); Cahse-Dunn (1989); Castells (1999) e Giddens (2002), que estudaram o fenômeno e produziram importantes análises a seu respeito; e igualmente, os estudos de Furtado (1998), lanni (1993, 2000), Ortiz (1994) e Dupas (2000), os quais ajudaram na obtenção de uma maior compreensão do tema, no Brasil.

Sendo um conceito relativamente novo, causando freqüentemente mitificaçã̃o pelos estudiosos quando visam compreender todo o contexto tecnosocial e suas implicações, é importante ressaltar, como assinalam Hirst e 
Thompson (1998, p. 13), que

é preciso acautelar-se contra as interpretações exageradas que constroem e divulgam a partir desses fenômenos reais. Tanto mais que esses exageros estão longe de serem politicamente inocentes. Ao contrário do que o uso generalizado do termo globalização ou mundialização da economia, os mercados nacionais continuam preponderantes, sobretudo nos países maiores.

Logo de início, nos deparamos com uma importante questão: como a globalização está relacionada com o surgimento e a consolidação das novas tecnologias de informação na América Latina? Esta correlação pode ser, em parte, explicada por Manuel Castells (1999, p. 87) :

uma nova economia surgiu em escala global nas duas últimas décadas. Chamo-a de informacional e global, para identificar suas características fundamentais e diferenciadas e enfatizar a sua interligação. É informacional porque a produtividade e a competitividade de unidades ou agentes nessa economia (sejam eles empresas, regiões ou nações) dependem basicamente de sua capacidade de gerar, processar e aplicar de forma eficiente a informação baseada em conhecimentos.

Porém, não devemos sucumbir a um encantamento pela técnica (as tecnologias da informação) e a descontextualização histórica dos novos discursos, os quais tornam discutíveis certas concepções construídas a partir da visão de alguns autores, entretanto úteis para entendermos essa nova realidade. A razão da mudança desses discursos, imperando a ideologia da técnica, é encontrada fazendo um recorte do próprio contexto histórico e econômico da América Latina nas duas últimas décadas. Este período é caracterizado pelos fluxos torrenciais de informação e capital entre países e empresas, com a descentralização dos comandos; a crise da democracia; o enfraquecimento dos direitos civis, criando o estado de não-sociedade e pondo-nos, em troca, grupos sociais e identidades fragilizadas e desprovidas das noções dos mais importantes direitos democráticos, articulados coletivamente.

$\mathrm{Na}$ cultura, por sua vez, surgem fortes indícios, trazendo a harmonização e homogeneização progressivas para a comunidade mundial, alavancados pelas forças da publicidade e a lógica do consumismo. Como bem observa lanni (2000, p. 17- |8),

é nesse sentido que a aldeia global envolve a idéia [...] de um shopping center global. Em todos os lugares, tudo e cada vez mais se parece com tudo o mais, à medida que a estrutura de preferências do mundo é pressionada para um ponto comum homogeneizado.

As novas tecnologias de comunicação, ao não visarem à produção de novos conhecimentos para a sociedade como um todo, propagam a ideologia dominante e os interesses de classes sociais preocupadas com a manutenção de seu status quo, carregando consigo um paradoxo presente na comunidade científica. É cada vez maior, sobretudo nas revistas científicas eletrônicas, a reprodução do (viciado) fundamento político de Francis Bacon que conhecimento é poder. E sobre o poder e seus abusos, parece que há uma perversidade nas 
bibliotecas brasileiras, pelo fato delas esquecerem o que teriam de mais nobre em sua missão e contribuição social, qual seja: o ato de possibilitarem potencialmente ou em ato - a repartição e distribuiçãa do conhecimento, dentro de um contexto muitas vezes não democrático. Embora tenhamos alguns discursos e esforços isolados, como o surgimento dos novos consórcios apontando ao rumo oposto, é certo que em muitas das bibliotecas preponderam a obediência aos regulamentos e políticas internos em detrimento da divulgação do saber, como se suas existências se justificassem por si.

No âmbito social, com a globalização e as novas tecnologias de informação, instaurou-se nas sociedades contemporâneas um ritmo de vida cada vez mais veloz, onde impera a instantaneidade da comunicação. Revela-se aí o deslocamento para um novo eixo espaço-temporal do cotidiano das diferentes sociedades. Com ele, estamos vivendo uma fragilização dos laços sociais, conseqüência da aceleraçãao das técnicas de comunicação. As cidades-estados criadas pelo uso intensivo das técnicas de comunicação produziram então uma ressonância que ecoa na forma da solidão múltipla para milhares de indivíduos de todo o globo. Como bem ilustram as palavras de Virilio (1996, p. 40),

Todos os homens sobre a Terra terão alguma oportunidade de se crerem mais contemporâneos que cidadãos e de evoluírem simultaneamente do espaço contíguo e contingente para uma velha Estado-nação (ou Cidade-Estado), abrigando o demos, para uma comunidade atópica do Estado: o Planeta.

Mas a análise de globalização não deve ser limitada apenas aos fatores políticos mencionados. Uma visão mais atenta dá conta de que, com a economia, temos o que se denomina como empresa transacional. Neste contexto, ela sugere uma transformação quantitativa e qualitativa do capitalismo além de todas as fronteiras, eliminando ou absorvendo outras formas de organização social e técnica do trabalho, da produção e da reprodução do capital. Entretanto, isso não implica em que as empresas e indústrias de manufaturas nacionais estejam virtualmente extintas, mas sim que elas passam, cada vez mais, a serem incorporadas a outras organizações maiores e em escala mundial. Como coloca Ortiz (I994, p. 15 e ss.), se entendemos por globalização da tecnologia e da economia a internacionalização das trocas, de produtos e de conhecimento, evidentemente não estamos diante de um fato original. Para ele, o mesmo pode ser dito a respeito da multinacionalização de empresas nacionais operando em uma escala internacional.

Além disso, as novas tecnologias permitem que o capital seja transportado de um lado para outro entre as economias, em curtíssimo prazo, de forma que o capital - e, portanto, poupança e investimentos - estejam interconectados ao redor do globo, de bancos a fundos de previdência, bolsas de valores e mercados de câmbio. Uma vez que as moedas são interdependentes, as economias de todas as partes do mundo também o são, aponta Castells (1999, p. II I). A empresa transnacional incita a criação de novos produtos internacionais; e o jornal, por exemplo, mais do que nunca, deixou de ser somente local para ser global e todos os acontecimentos exteriores refletem nos nossos dias na economia, política e sociedade locais de maneira vertiginosamente mais rápida e incisiva. Se as políticas dos governantes estão despreparadas para esta nova realidade, o que dizer de uma economia calcada em movimentos globais? 


\section{0 mercado de publicações científicas}

Este desalinhamento entre as diversas regiões do globo e internas de cada país, sentido por disparidades socioeconômicas, é agravado pelas mudanças no fluxo da produção do conhecimento científico e, sobretudo, devido às mudanças ocorridas com as publicações científicas eletrônicas, contribuindo para o fenômeno da infoexclusão. No caso da Internet, defrontamo-nos com uma faca- de-dois gumes, pois, como comenta Ataíde (1997, p. 4), sua natureza permite que as informações sejam colocadas de forma desorganizada e, conseqüentemente de difícil recuperação, onde "grupos possam juntar-se e criar sites com informações organizadas, com valor agregado, estratégicas e disponíveis", e a quem puder pagar por elas.

E não foi somente a hipertextualidade que, a partir de um determinado momento histórico, outorgou às publicações periódicas eletrônicas um lugar de destaque nas comunidades científicas. Fatores econômicos, como os mencionados anteriormente, impulsionaram os grandes agentes distribuidores ou agregadores a contribuir para que o mercado de publicações periódicas impressas entrasse em uma crise sem precedentes no mundo e aflorasse o mercado das publicações eletrônicas. Como relatam diversos autores, tal comportamento econômico do mercado ocorreu sobretudo nos últimos anos. Entre estes, estão os trabalhos de Odlyzko (1997), Brakel (1995), Schauder (1994), Meyer (1997) e Rogers e Hurt (1990), que levantam as possíveis causas para este fenômeno:

- $\quad$ ineficácia do modelo tradicional: as informações científicas chegam ao seu público-alvo através de outros meios antes de sua efetiva publicação. Assim, quando um artigo é publicado este não representa uma novidade, informa Brakel (1995);

- limites físicos: alguns artigos, que poderiam trazer informações novas e relevantes, acabam não sendo publicados, devido à falta de espaço nas edições impressas. Este é o resultado obtido em uma pesquisa conduzida por Schauder, segundo a qual 35\% dos acadêmicos entrevistados afirmam defrontar-se com o problema (1994);

- $\quad$ alta especialização e baixa circulação: há uma tendência global que torna excessivo o número atual de revistas cientíicas (algo típico da explosão informacional, característico das sociedades atuais), onde cada título, com raríssimas exceções, têm um público extremamente limitado e elitista. É o caso, por exemplo, de um pequeno grupo de revistas altamente conceituadas, porém elitistas, quanto a quem e o que nelas se publica, como no caso dos títulos Nature, New England Journal of Medicinee Science, somente para mencionar três exemplos, como arrolam Rogers e Hurt ( 1990);

- $\quad$ altos e crescentes custos: a própria especialização e dificuldades ligadas à editoração forçam as publicações a terem tiragens pequenas e, como conseqüência, um baixo número de assinantes, criando assim um círculo vicioso que contribui para a elevação de custos e a inflação dos preços observados, indicam, em seus estudos, Brakel (1995), 
Schauder (1994), Meyer (1997) e sobretudo Odlyzko (1997);

- falta de espaço para armazenamento nas bibliotecas: o problema é comum às grandes universidades brasileiras, representando um custo adicional aos orçamentos locais. Assim, até o espaço particular de serviços de referência e consultas acabam sendo, de um modo ou de outro, afetados, criando distúrbios aos pesquisadores em suas atividades.

No caso dos grandes agentes distribuidores atuantes na América Latina (Swets-Blackwell, Ebsco Information Services, Elsevier Science etc.), encontramos um mercado global caracterizado pela existência de um oligopólio ou monopólios onde exercem o poder duas ou mais empresas distribuidoras fornecendo diversos serviços de informação, entre eles o de periódicos científicos. Paralelamente, encontramos na literatura uma preocupação e interesse crescentes - sobretudo com a publicação eletrônica - dos seguintes autores entre tantos em seus estudos: Meadows (1979, 1997); Harrison e Stephen (1995); Barreto (1998); ou a extensiva bibliografia publicada [ainda] regularmente por Bailey Jr. (2003).

Um aspecto pouco abordado na literatura internacional relaciona-se as atividades dos agentes distribuidores e grandes editores e suas respectivas metas comerciais - envolvendo o controle monopolístico e sua expansão no mercado internacional - estão relacionados com as dificuldades nas atividades de seleção e compra de periódicos científicos, e poucos são os artigos que abordam diretamente esta questão. Entre as exceções, são os estudos de Schauder (1994), e sobretudo Meyer (1997). Meyer aprofunda-se em suas pesquisas sobre a questão dos monopólios e busca enumerar algumas das razões para o problema do ponto de vista econômico, atrelado à questão do aumento de custos para as bibliotecas e, indiretamente, as atividades dos consórcios. Deste ponto de vista, a inflação é um sério problema pois sua taxa de crescimento excede a habilidade das bibliotecas de lidarem com o problema. Neste sentido, várias análises foram feitas buscando solucioná-lo, como o estudo de Kingma Eppard (1992), que apontaram como saídas os subsídios federais, reclamações aos fornecedores, aumento da taxa de fotocópias, convencimento de administradores de universidades e instituições para um incremento dos orçamentos de bibliotecas, e mudança do acesso versus posse.

Porém, serão a inflação e os altos custos praticados pelos agentes distribuidores os únicos componentes nesta história de vilões?. Tudo indica que não. Conforme aponta Meyer (1997, p. 327) em seu estudo, "infelizmente para as bibliotecas, a demanda de usuários para qualquer que seja um dado periódico é comumente inelástica". Meyer (1997, p. 327 e ss.) ainda define inelasticidade como sendo,

um termo econômico que descreve a inclinação da função demanda. Em um gráfico onde o eixo vertical representa o preço e o eixo horizontal representa a quantidade, a demanda declina-se com o acréscimo quantitativo. [...] Como os preços sobem, a demanda oscila muito pouco. Funções da demanda altamente elásticas são próximas da linha horizontal. Muito baixo crescimento nos preços resulta em uma significante variação da demanda. 
atributo da elasticidade é muito importante para então entendermos as variações da demanda em função da flutuação de preços no mercado de periódicos científicos. Segundo o raciocínio de Meyer (1997, p. 337), sobre a inelasticidade da demanda e o jogo exercido pelos detentores dos monopólios do mercado,

novas pesquisas podem confirmar que grandes editores estão hábeis para reter os monopólios do poder com as contrapartes eletrônicas de seus periódicos científicos. [...] Um trabalho usando um modelo alternativo tem examinado a possibilidade de que grandes editores exercitam o monopólio do poder no estabelecimento de preços. A teoria prediz que em um mercado competitivo, sempre quando é caracterizada uma competição como monopolística, o preço oferecido a usuários individuais será elástico. Por substituição da medição do monopólio do poder pelo papel dos preços, tem sido mostrado que grandes editores têm alguma habilidade para influenciar os preços através da discriminação dos mesmos. (...) Havendo um aumento dos preços para indivíduos, alguns [ou muitos] deles cancelarão suas assinaturas pagas de próprio bolso em favor do acesso eletrônico pela biblioteca. Isto é, o preço de periódicos para indivíduos é uma determinante da demanda de acesso eletrônico nas bibliotecas.

Sob outra ótica mais ampla, analisando a questão dos monopólios da indústria de publicações científicas - cujos atores são também denominados information players, é oportuna a colocação feita por Mello (1999, p. 173) para monopólios:

a concorrência econômica não é [a princípio] o contrário de uma ordem monopolista, como observa corretamente Norbert Elias. Apenas que, pela própria dinâmica contraditória do movimento de acumulação do capital, esta concorrência transcende seus próprios limites e se converte em seu contrário.

No texto, o autor deixa evidente que as relações comerciais estão cada vez mais pautadas pela formação de grandes conglomerados monopolistas, atuantes no Brasil em todos os segmentos de mercado. A falsa existência de uma concorrência, que somente o é por converter-se em seu contrário e por acirrar a disputa, na outra ponta, das relações sociais existentes: a da grande massa de pesquisadores e demais usuários ávidos por informações, estas cada vez mais disponíveis, porém com preço mais elevado e através de um grupo menor de bibliotecas ou instituições, dado o seu alto custo de acesso e/ou posse. Neste contexto, os consórcios de bibliotecas parecem inclinar o equilíbrio em prol das instituições de pesquisa e informação, tornando-as capazes de possuir grande poder de negociação ao tratar com os grandes conglomerados (information players) do mercado de periódicos científicos. Ainda que os consórcios tenham surgido, historicamente, em meados do século XVII nos Estados Unidos, a atividade destes information players é relativamente nova no Brasil - de meados da década de 80 - e somente agora, devido ao aumento de preços de periódicos, houve um processo de crescimento de suas atuações em nosso país, semelhantemente ao que ocorre no restante do continente latino-americano. Por meio da leitura de relatórios financeiros anuais e parciais, 
de pesquisa na literatura existente, e de contatos com diversos colegas bibliotecários, foi possível colher informações que comprovam a existência de dois grandes oligopólios do poder, formado pelos information global players. Estes são atuantes em diversos mercados espalhados pelo mundo, e controlam a quase totalidade do mercado local brasileiro de produtos informacionais para bibliotecas especializadas e universitárias, conforme atesta o estudo de Amorim (2002, p. 6I-62), cuja arquitetura ainda não diverge muito do quadro em 2005. O monopólio da empresa Wolters Kluwer, com sede na Holanda, e o da Thompson Corporation, com sede nos Estados Unidos. A Wolters Kluwer foi formada em 1987, pela junção da Wolters Samsom com a Kluwer, após tentativa de compra pela Elsevier, no mesmo ano, das ações da Kluwer.

\section{A situação dos consórcios de bibliotecas na América latina}

Há indícios de crescimento, porém ainda é pequeno o número de consórcios de bibliotecas latino-americanas de maior vulto, visando, sobretudo, à economia na aquisição de publicações científicas. Uma característica marcante deste mercado é a presença de alguns consórcios com um certo tempo de vida, resistentes às intempéries do mercado e mantendo portais eletrônicos operando como grandes catálogos de revistas científicas para seus usuários. Entre estes consórcios, podemos destacar:

- no Brasil: o consórcio nacional de periódicos eletrônicos da Capes, criado no final de 1999. A Coordenadoria de Aperfeiçoamento de Pessoal do Ensino Superior (CAPES) é a instituição pública governamental responsável pela formação de pesquisadores e pela concessão nacional de projetos e bolsas de pesquisa no país. A instituição formou este consórcio assumindo integralmente a responsabilidade pela compra de grande parte das revistas científicas de agentes de revistas e distribuidores às bibliotecas brasileiras participantes - em 1999, com 85 bibliotecasmembro. Toda a articulação política fora feita pela Comissão Brasileira de Bibliotecas Universitárias - CBBU -. Nestes últimos dez anos, o relacionamento entre a CAPES e os participantes do consórcio em geral, fora caracterizado por diversos problemas, marcados pela demora e desentendimentos no repasse das verbas a estas instituições. Outro fato marcante desse período e que afetou a aquisição de periódicos no país como um todo foi a forte crise cambial ocorrida ainda em 1999. Porém, em meados de 2000, uma mudança positiva nos rumos do consórcio influenciada pela entrada massiva dos periódicos científicos eletrônicos no mercado brasileiro e a criação de uma infra-estrutura tecnológica do órgão gerenciador, dando o suporte que faltava ao consórcio. Em setembro de 2005, o consórcio possibilita o acesso a cerca de 9.444 títulos eletrônicos e a dezenas de bases de dados referenciais disponíveis pelo portal CAPES (http:/ Mww.periodicos.capes.gov.br/), e oferecidos a I 63 instituições, sejam de ensino superior ou outras, com acesso restrito às coleções contratadas. 
- o consórcio CODESAN - INFOANDINA - Consórcio para el Desarollo Sostenible de la Ecorregión Andina -: Estabelecido em 1993, este consórcio atuante na região andina, compreendendo o Peru, Equador e Bolívia têm, como objetivo principal, a difusão dos resultados de pesquisa de seus membros, feita principalmente por boletins e relatórios eletrônicos. Visando também a cooperação científica com todos os países latinoamericanos e do Caribe, está disponível no site: http:// www.condesan.org/bgris/index.htm. Seu principal patrocinador financeiro é o Centro de Investigação Internacional do Desenvolvimento - IDRC, do Canadá.

- $\quad$ SIDALC - Sistema de Información y Documentación Agrícola de América Latina y el Caribe (Agricultural Information and Documentation System of the Americas): com sede na Costa Rica, iniciou suas atividades em 1991, ainda que sua concretização ocorrera somente em 1998, com a catalogação automatizada de links para textos completos de periódicos da área abrangendo todos os hemisférios do continente. O consórcio SIDALC teve novo impulso em fevereiro de 2000, quando do Taller Conformación del Consorcio de Bibliotecas del Sistema de Información y Documentación Agropecuaria de América Latina y el Caribe, em Monterrey no México. O SIDALC tem como site principal: http://orton.catie.ac.cr/ e é composto em 2004 por vinte e oito instituições de informação científica agropecuária de todas as Américas, incluindo uma da Espanha. Tem como membro coordenador geral o Instituto Interamericano de Cooperación para la Agricultura - IICA -, com o suporte financeiro da Fundação W. K. Kellog, dos Estados Unidos (disponível em português no site: http://www.wkkf-lac.org/home.aspx?LanguagelD=2). Sua principal fonte de informação é uma metabase de dados agrícola denominada Agri2000, sob a responsabilidade da instituição costariquenha Biblioteca Conmemorativa Orton (IICA/CATIE);

- $\quad$ o Consorcio Iberoamericano para la Educación en Ciencia y Tecnología - ISTEC - Ibero American Science \& Technology Education Consortium -: criado em 1990, é um dos maiores consórcios da América Latina em abrangência, composto por várias instituições acadêmicas e sete indústrias - disponível na Internet no site: http://www.istec.org/. Fazem parte deste consórcio instituições da Espanha, Portugal e Américas e sua rede cooperante é bastante conhecida e referenciada na literatura, o LibLink (Library Linkages). O Liblink é uma das iniciativas do ISTEC para toda a comunidade Ibero-americana. Tem como meta de longo prazo promover a criação e uso de serviços compartilhados de informação através da Internet. É uma organização sem fins lucrativos, e composta por indústrias (a Microsoft, a Sun Microsystems, a Motorola, a Hewlett Packard, entre outros), centros de pesquisa e investigação e membros institucionais (a OEA, O Banco Interamericano do Desenvolvimento - IDB, a UNESCO, a ONU, entre outros), 
atuando tanto nas Américas como na península Ibérica. 0 consórcio foi fundado com a finalidade de acelerar o desenvolvimento econômico da América Latina mediante o fomento da educação nas ciências, engenharia e tecnologia; realizar projetos internacionais de pesquisa e desenvolvimento e possibilitar uma ferramenta efetiva para a transferência de tecnologia. Dentre os membros acadêmicos, destacam-se: Universidad Mayor de San Andrés, Bolívia; Instituto de Tecnologia de Aeronáutica- ITA -, Brasil; Pontifícia Universidade Católica do Rio Grande do Sul, Brasil; Universidad Autónoma de Baja Califórnia, México; Universidad Nacional La Plata, Argentina; Universidade Federal do Rio de Janeiro, Brasil; Universidade Estadual de Campinas, Brasil; Universidade Estadual Paulista - UNESP-, Brasil; e a Universidad de Chile.

Após este panorama dos principais consórcios que atuam na América Latina, é apresentado um estudo de caso de um consórcio específico, o consórcio ProBE - Programa Biblioteca Eletrônica -, iniciativa muito importante nos últimos anos por representar a maior fonte de revistas científicas eletrônicas para os pesquisadores brasileiros, em todos os campos do conhecimento, que tem seu centro na Fundação de Amparo à Pesquisa do Estado de São Paulo.

\section{Estudo de caso: as liç̃̃es de um consórcio de bibliotecas no Brasil}

A seleção do Consórcio ProBE - Programa Biblioteca Eletrônica - para este estudo de caso, dentre os poucos consórcios existentes no mercado brasileiro, foi baseada em critérios como:

- $\quad$ habilidade de negociação com os agentes distribuidores de revistas científicas e/ou diretamente com seus editores;

- tempo de vida do consórcio e sua habilidade política para atuar como um organismo empreendedor em relação às instituições participantes do Consórcio, considerando as peculiaridades e diferenças em suas linhas de ação, bem como as características de seus dirigentes.

É importante destacar que, por ocasião da opção pelo Consórcio ProBE como estudo de caso, o consórcio CAPES estava ainda recém iniciando suas atividades no Brasil e tinha, como uma de suas maiores restrições, a exclusão de participação das bibliotecas das três universidades públicas do Estado de São Paulo, sendo, por este motivo, naquele momento menos amplo que o ProBE, o qual permitia a participação de todas as bibliotecas. De parte do consórcio CAPES, uma das explicações dadas para justificar a exclusão das bibliotecas universitárias destas universidades era a situação em que se encontravam as universidades federais, que necessitavam de apoio financeiro para a aquisição de revistas científicas, enquanto que as bibliotecas do estado de São Paulo, pelo contrário, eram exatamente as bibliotecas líderes, que possuíam os 
maiores orçamentos para a compra de revistas em todo o estado e, provavelmente, de toda a região sudeste do Brasil. No entanto, alguns meses mais tarde, ocorreram algumas mudanças na política da CAPES, no que diz respeito a estas bibliotecas, que passaram a ser integradas a este. $\bigcirc$ consórcio ProBE se manteve em atividade até junho de 2002, quando foi descontinuado. A partir desta data, a CAPES se transformou no maior consórcio brasileiro até os dias atuais, tomando o lugar do Consórcio ProBE como portal referencial de revistas de todas as áreas do conhecimento às bibliotecas.

\section{Metodologia}

As seguintes ferramentas metodológicas foram utilizadas para a coleta de dados no estudo de caso:

a) Pesquisa e leitura dos documentos oficiais do consórcio;

b) Entrevistas e questionários submetidos aos principias líderes e profissionais relacionados ao Consórcio ProBE, de acordo com um guia pré-estabelecido (que foi submetido, como um pré-teste, a um bibliotecário não-participante da pesquisa), bem como questionários submetidos aos principais agentes distribuidores internacionais de revistas científicas com escritórios no Brasil.

c) Análise e relatório das principias atividades do consórcio, por meio do acompanhamento das atividades de sua comissão dirigente;

d) Coleta de informações dos sites oficiais dos principais agentes distribuidores que participaram deste consórcio na América Latina;

e) Análise dos fatores relacionados ao contexto mundial e o brasileiro, para melhor avaliação dos fatos relativos ao consórcio.

\section{Resultados}

Em seu período enquanto projeto piloto, o Consórcio ProBE conforme descrito em documento produzido em seu II Workshop (Programa Biblioteca Eletrônica, 200I) - reuniu as cinco universidades públicas paulistas (Universidade de São Paulo - USP, Universidade Estadual Paulista Júlio de Mesquita Filho - UNESP, Universidade Estadual de Campinas - UNICAMP, Universidade Federal de São Carlos UFSCAR, Universidade Federal de São Paulo - UNIFESP), e o Centro Latino-Americano e do Caribe de Informação em Ciências da Saúde BIREME, visando naquele instante à compra de 606 títulos eletrônicos da Elsevier Science, sendo pouco mais de uma dezena de títulos da HighWire Press e mais de 100 títulos da então Academic Press. 0 Consórcio ProBE era gerenciado por um comitê gestor composto por três bibliotecárias, uma das quais se dedicava, em tempo integral, ao 
consórcio; um representante de cada instituição-membro fundadora (USP, UNICAMP, UNESP, UNIFESP e UFSCAR) e consultores técnicos e jurídicos de todas as partes envolvidas. Além das instituições fundadoras - aquelas universidades que participaram do período piloto do consórcio - juntaram-se outras instituições de pesquisa ao projeto, trazendo a este uma dimensão política única no país naquele momento. $\bigcirc$ consórcio cresceu aos poucos, devido ao rápido sucesso do acesso aos textos completos desses títulos eletrônicos: de acordo com o relatório de seu comitê gestor, em novembro de $200 \mathrm{I}$, ele atingia a meta de oferecer 2.260 revistas científicas de nove editores diferentes, a uma comunidade de 145.613 pesquisadores, congregando uma rede de 132 bibliotecas de $4 \mid$ instituições e um orçamento global de US\$ I ,500,000.00 dólares, conforme atesta o Programa Biblioteca Eletrônica (200 I).

Os resultados obtidos evidenciaram que as bibliotecas realizavam a atividade consorciada atingindo um novo patamar quanto aos seus programas de desenvolvimento de coleções. Tal constatação foi corroborada pelas diversas opiniões coletadas, que denotaram:

- $\quad$ a conscientização da importância, por parte de cada biblioteca ou instituiçãa, de manterem e ampliarem o acesso compartilhado, bem como a ciência das novas dificuldades com as quais se depararam, num contexto marcado pela crescente migração do periódico científico para o meio digital. Isto ainda que esta migração não possa em médio prazo ser concretizada em sua totalidade para o mercado latinoamericano;

- $\quad$ foi possível inferir que o fator anteriormente apontado interferiu diretamente na construção e reformulação do modelo de compras utilizado até então pelas bibliotecas em suas políticas de desenvolvimento de coleções, as quais, dependendo das políticas institucionais ditadas por suas universidades, tenderam a facilitar o acesso à informação científica para um universo mais amplo de usuários (pela idéia de informação enquanto um bem público).

Houve saudável discordância e diferenciação entre as instituições do consórcio, no que diz respeito a alguns dos pontos de suas políticas de desenvolvimento de coleções, em conseqüência da atividade consorciada. Isto evidenciou as novas interações políticas e econômicas possíveis entre as instituições como elementos agentes de todo o processo cooperativo. $\mathrm{Na}$ medida do possível, cada instituição tentou adaptar seus serviços oferecidos à realidade criada pelo consórcio, diversificando-os pelo aumento das coleções de revistas científicas com acesso eletrônico, com grande parte delas tendo impacto em suas respectivas comunidades acadêmicas. Esta modificação foi uma reação das bibliotecas para manterem as suas sobrevivências financeiras, agravadas pela alta dos preços de títulos e, em conseqüência, a inelasticidade da demanda pelo uso.

No entanto, a análise do consórcio ProBE durante sua existência evidenciou que ele cumpriu parcialmente seus objetivos, enquanto órgão administrativo e empreendedor na condução deste grupo de bibliotecas pela ação de sua liderança política relativamente forte, algo não ocorrido nos anos seguintes. Uma das ressalvas a ser feita e comprovada por depoimentos da coordenadoria do consórcio foi a dificuldade do mesmo em repassar as suas 
diretrizes de execução às bibliotecas participantes pela utilização de um marketing mais ativo, com a divulgação de todas as suas atividades, permitindo assim uma maior e mais rápida disseminação dos recursos eletrônicos existentes, a fim de torná-lo uma atividade constante nestas instituições-membro do consórcio.

\section{Consideraç̃̃es finais}

No plano macro-econômico, a globalização e a info-exclusão são elementos que aumentam a responsabilidade social e exigem das bibliotecas universitárias brasileiras (como também de toda a América Latina) que repensem suas políticas de desenvolvimento de coleções. Estas devem estar alinhadas com as iniciativas de fomento dos projetos de pesquisa e de desenvolvimento existentes em seus respectivos países, já que o quadro latinoamericano ainda necessita de novas e fortes iniciativas fortalecendo sua produção científica, e possam contribuir para atingirem melhores níveis de competitividade, bem como promovam maior eqüidade social ultrapassando as respectivas limitações destas nações, e alcançando melhores patamares econômicos e sociais que os atuais.

Neste contexto, o desenvolvimento de acordos cooperativos de produtos e serviços assume grande importância, no qual se insere a atividade dos consórcios para a aquisição e acesso aos periódicos científicos eletrônicos. Isto permitirá a estas bibliotecas enfrentarem, por um lado, uma realidade hostil às bibliotecas com a ação do monopólio de publicações científicas e, por outro lado, um contexto social, tecnológico e econômico caracterizado pela globalização de mercados, e, num âmbito maior, por processos político-sociais que dificultam a democratização do acesso ao conhecimento.

Parece haver ainda um tipo de perversidade nas (e com as) bibliotecas brasileiras, pelo fato de elas não poderem cumprir a mais nobre parte de suas respectivas missões e contribuição social: o fato de possibilitarem (em potência e ato) a repartição e distribuição do conhecimento, num contexto antidemocrático. Embora a iniciativa esteja presente em muitos discursos e alguns esforços isolados como o surgimento de novos consórcios, apontando no rumo oposto, é certo que na maioria das bibliotecas prepondera sobremaneira a obediência às regras e políticas internas, em detrimento da divulgação do saber, como se suas existências se justificassem por si mesmas. Neste caminho, há uma barreira cultural e política (ainda) a ser quebrada pelas bibliotecas universitárias brasileiras.

\section{Library consortia in Brazil: a challenge to knowledge democracy}

Discusses the impact of the electronic globalization and the role of library consortia in Brazil as an element of information democratization. Analyses the scientific journals market and describes the main recent Latin-american library consortia. Accomplishes a case study of a brazilian library consortium - the 
Probe -, and its benefits to brazilian libraries and to the scientific community, as some considerations about its impact on the promotion of higher social equity.

Key-words: Library consortia - Brazil; Probe consortium; Scientific journals Globalization; Electronic journals.

\section{Referências}

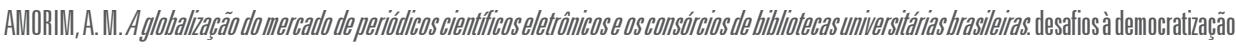

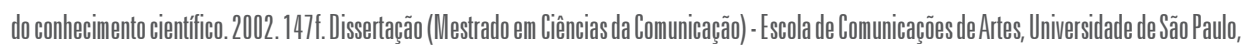
São Paulo. 2002.

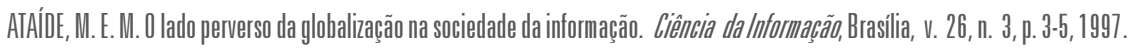

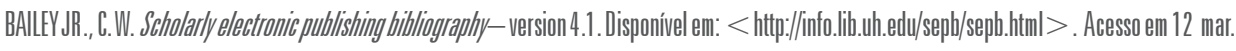
2001.

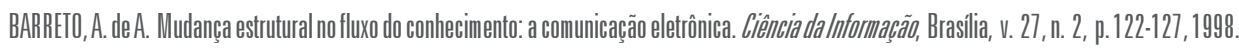

BRAKEL, P. . . V. Electronic journal: publishing via Internet's SWWW. Hectronic Library, Bradfford, v. 13, n. 4, p. 389-395, 1995.

CAHSE-DUWW, C. Globalformation. structures of the world economy. Oxford: Basil Blackwell, 1989.

CASTELlLS, II. A socieddade elll rede. In:

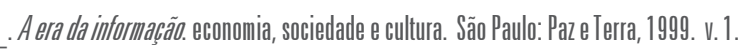

CONEXã̃ em ritmo frenético. Follha de S. Paullo, Jão Paulo, 21 out. 2004. Revista Top of Mind, p. 40.

DOSI, G. et al. (Org.). Technirica/change andd econominic theory. London. Pinter, 1988.646 p.

DUPAS, G. Economimia global/e excllssão social. pobreza, empregyo, estado o o futuro do capitalismo. 2. ed. São Paulo: Paze e Terra, 2000. 241 p.

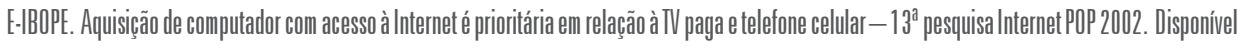
em: $<$ http://www.ibope.com.tri / > Acesso em 15 jul. 2002.

FURTIADO, C. O C capitialismo globbal. São Paullo: Paze Terra, 1998. 81 p.

GIDDEIIS, A. Rullaway world. how globalisation is reshaping our lives. London: Profile, 2002. 104 p.

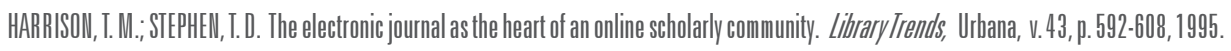

HIRST, P:- THOMPSOW, G. The problem of globalization: international economic relations, national economic manangement and formation of trading blocks. Economy and Society, London, v. 21, n. 4. p. 357-96, 1992.

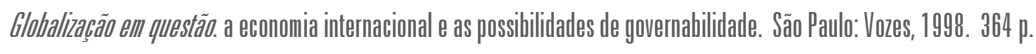

IAlll|, 0. A sociedadale global. 2. ed. Rio de Janeiro: Civilizaçāa Brasileira, 1993. 194 p.

. Teorias dla globalliząâa. 8. ed. Rio de Janeiro: Civilizaçăo Brasileira, 2000.228 p. 
KIMGMA, В.; EPPARD, P. Journal price escalation and the market for information. the librarians' solution. College and research libraries, Chicago, v. 53, n. 6, p. $523-535,1992$.

MEADOWS, A.J. (Ed.). The scientificjourrnal. London: Aslib, 1979. 300 p. (Asilib Reader Series, 2).

MEADOWS, J. Can we really see where electronic journals are going? Library Management, Bradford, v. 18, n. 3, p.151-154, 1997.

MELLO, A. F. de. Marx e a globalização. São Paulo: Boitempo, 1999. 286p.

MEYER, R. W. Monopoly power and electronic journals. Library Quarterly, Chicago, v. 67, n. 4, p. 325-349, 1997.

NOGUEIRA, C.:VARGAS, N. A radiografia da internet brasileira. Veja, São Paulo, n. 1672,25 out. 2000. Disponivel em: < hittp://www2.uol.com.br//veja/ 251000/p_136.html>. Acesso em 12 nov.2000.

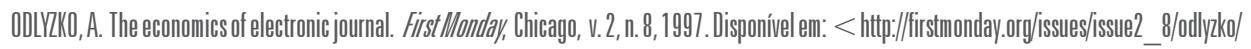
index.html > . Acesso em 10 jul. 2001.

ORTIZ, R. Mundialização e cultura. São Paulo: Record, 1994. 234 p.

PROGRAMA BIBLIOTECAELEtrônICA. Relatório ProbE. São Paulo: ProbE, 2001. Disponivel em: < hittp://www.probe.br/probe-histhtm > . Acesso em 20 jul. 2001.

ROGERS, S.; HURT, C. S. How scholarly communication should work in the 21 st century. College and Research librarries, Chicago, v. 51, n. 1, p.5-8, 1990.

SCHAUDER, D. Flectronic publishing of professional articles: attitudes of academics and implications for the scholarly communication industry. Journal of the American Society for /nformation Science, New York, n. 45, p.73-100, 1994.

VIRIILO,P. A arte do motor. São Paulo: Estação Liberdade, 1996. 134 p. 